\title{
Factors in the Success of Small Farms and the Relationship Between Financial Success and Perceived Success
}

\section{Michael Duffy and Virginie Nanhou Iowa State University ${ }^{1}$}

Agriculture is changing rapidly in the United States. New technologies, consolidation, environmental concerns and food safety are some of the factors that contribute to change and uncertainty. Change has always been a part of the American scene. But, the pace of change has increased and not everyone is convinced that the changes are taking us in the right directions.

One concern being voiced relates to the loss of farmers and the corresponding increase in farm size. In 1997, this concern led then-Secretary of Agriculture Dan Glickman to form a Small Farms Commission. The charge for the Commission was to examine ways that 'small farms can compete in a large economy.'

Some see the concern over small farms as a nostalgic yearning for the past. However, others are alarmed about small farms and their fate because these operations represent such a significant portion of all U.S. farms. In 1998, 91 percent of all U.S. farms were classified as small farms and these farms accounted for 68 percent of all land owned by farmers.

Critics of the concern over small farms contend that the worries are misplaced. They argue that farms are growing larger to capture economies of size. This is the way of an efficient market. And, small farms are in actuality simply rural residents, retirement farms, or some other aberration. They are not 'real farms.'

It is apparent from examining the trends that farms are getting larger. It is equally apparent that some farms are successful in spite of their size.

The question we wish to address is why some small farms are more successful than others. In addition, we will discuss briefly the differences between our perception as researchers of successful farms and the perceptions of the farmers themselves as to their level of success.

\section{Definitions}

The current U.S. Department of Agriculture (USDA) definition of a farm is any place that sells or normally would have sold $\$ 1,000$ of agricultural products in a year. Sales volume has been used to determine what constitutes a farm for decades. The current cutoff of $\$ 1,000$ has been used since 1974 .

Using such a low dollar sales figure to define what constitutes a farm means that we include many units that would not be considered a farm on their own. For example, in Iowa, based on the 1997 Census of Agriculture, 10 percent of all farms actually had sales less than $\$ 1,000$. They were included simply because they had an inventory worth $\$ 1,000$. In addition, 4 percent of Iowa's farms had sales between $\$ 1,000$ and $\$ 2,500$.

\footnotetext{
${ }^{1}$ This work was funded in part by a grant from the USDA Economic Research Service
} 
The current definition of what constitutes a farm leads to distortions when trying to analyze and interpret agricultural statistics. The definition masks the trend of the disappearing midsize family farms. It also makes evaluating and formulating agricultural policy difficult. For example, there were questions raised recently about the distribution of direct government payments. In Iowa, 80 percent of the farms received just 30 percent of the payments. But, are the 14 percent of Iowa's farms with sales less than $\$ 2,500$ really the ones for whom the help was intended? Who are the intended recipients of aid and are they the ones receiving it? It is difficult to know with the current definition of a farm. The definition also is part of the problem in a discussion of whether or not small farms can compete.

The problem of what constitutes a farm is further exacerbated due to changing numbers provided by the USDA. The 1997 Census put the number of Iowa farms at 90,792. However, in 1999, the USDA revised this number to 98,000 farms, a difference of 8 percent.

In addition to defining a farm determining what is or isn't a small farm is equally daunting. There are many different ways to measure farm size. The Small Farms Commission chose to use sales. Farms with sales of less than $\$ 250,000$ were considered small farms.

What is truly a farm or a small farm invites considerable debate and discussion. Arguing one way or the other is not our intention. We feel a better definition can be found. Simply increasing the minimum level of sales needed would be more reflective of the current situation. Discussion of an alternative definition, however, is the topic for another paper. This paper simply uses the current definitions. A farm is any place with sales greater than $\$ 1,000$ and a small farm is a farm with sales of less than $\$ 250,000$.

For much of this paper we will be equating success with the level of a profit index. We do so under the assumption that one of the major goals of the farm is to earn a profit. We use a profit index, rather than actual profit level, because using the absolute level of profit will automatically introduce a size bias.

The profit index used is defined as:

$$
\begin{aligned}
& \text { PI = GP / (GP }- \text { MR }) \text { where: } \\
& \text { PI = Profit index, } \\
& \mathrm{GP}=\text { Gross profits which is the dollar value of the activities for the farm, } \\
& \text { and } \\
& \mathrm{MR}=\text { Management return or the return over all costs, including a charge } \\
& \text { for unpaid labor and owners' equity. The management return can } \\
& \text { be thought of as pure profit. }
\end{aligned}
$$

The profit index is a measure of how efficiently the farm uses its resources. If the profit index is greater than one, the farm made more money than the value of the resources it used. In other words, the farm would have a positive management return. 
The use of the profit index allows us to extrapolate from the overall size of the farm when we are making our determination of whether or not the farm is successful. If the farm has a positive management return (profit), we consider it successful regardless of the level of the return.

\section{Theoretical Considerations}

Economies of size constitute the major argument for why a large farm is more efficient than a small farm. Under economies of size, the cost per unit decreases as the level of output increases. In other words:

Percent change in costs/percent change in output $<1$

Economies of size occur primarily because fixed costs can be spread over more units of output, decreasing the cost per unit. At some point, costs will no longer decrease and in some cases they may even increase as resource constraints are encountered.

A major issue arises in discussions of small farms and their ability to compete when the decreases in costs cease to occur. Data from the Iowa Farm Business Association suggest that for conventional Iowa row crop farms the decreases in the average cost per unit generally end between 400 and 600 acres. Beyond this, the average cost curve remains relatively flat. The existence of such " $L$ " shaped average costs curves has been observed in most agricultural enterprises. (Hallam, 1993)

The level at which the economies of size cease depends upon many factors. The most important factor is the type of enterprise being considered. Small farms will be more successful when they pursue enterprises where the economies of size are realized with lower levels of production.

An attribute of farms, especially small farms, is that they are almost universally part of a household. This condition has implications for measuring success.

Farm income may only be a small part of the household's total income. In many cases whether or not the farm makes money is almost irrelevant. Generally, the farm is expected to not lose money, but for some the contribution the farm makes to the household's total income is marginal.

There are an estimated 1.2 million farms in the United States. Of these farms, 43 percent are classified as rural residences. This means they have sales of less than $\$ 250,000$ and they list something other than farming as their principal occupation.

Retired farmers are another subset of farm operations. These farms have less than $\$ 250,000$ in sales annually and they provide supplemental income to the household. Fourteen percent of all farms were classified as retirement farms.

A majority of all farms (57 percent are either rural residences or retirement farms) do not rely solely on their farm income nor do they view farming as the principal 
occupation. Given these observations, it is important to note that the goals of the farm may vary considerably from a traditional small business.

Economists assume profit maximization is the goal for the farm. This assumption greatly simplifies analysis, discussion, and comparisons. However, analysis based on profit maximization may not be valid if profit is only one of several considerations for the decision maker. For example, sheltering other income from taxes may be a significant component of the decision.

The farm very often has two interconnected dimensions: the farm, whose main objective is profit; and the household, whose main objective is to maximize the utility of the family members. Since the farm family most often lives on the farm, it is generally difficult to separate the farm from the household. So making profit becomes just one factor in the utility function. Other elements in the utility function can be job and family satisfaction (Ajwa, 1991) or aspects such as power, control prestige and desire for a quiet life. (Gasson et. al., 1988).

Profit is a convenient attribute for analysis of farms. It is observable and not subject to individual interpretation. Therefore, it is the most often used measure of success or failure.

This paper features two main foci for analysis. First, we will compare and contrast successful and unsuccessful small farms. Such comparisons have been conducted many times in the past. (Mosher and West, 1952; Garcia, et al., 1982; Fox, et al., 1993; Hoffman R., 1996; Mishra et al., 1999; Perry and Johnson, 1999) Our study is a departure from the previous work in that we examine success based on a profit index as an indicator of efficient resource use rather than the absolute level of profits.

A second focus will be to examine differences between the more traditional measures of success and the farmer's own perception of whether or not they are successful. If profits are not the sole measure this analysis should reveal the differences. Before proceeding we will describe the data used for this analysis.

\section{Data}

The data used in this study come from the Iowa Farm Business Association (FBA), an organization of approximately 3,100 farmers throughout Iowa. The purpose of the organization is to provide record-keeping, financial analysis, and tax preparation for the members.

Two data sets from the FBA were used. The first data set contained the financial records of the farms. This data set included the assets and liabilities for the individual farms as well as the level and costs of production.

The second data set was a telephone interview with the selected FBA members. The Iowa Agricultural Statistics Service conducted these interviews to gather socioeconomic data related to the farm. 
There were 1,500 farms with complete financial data covering each year for the period 1991 to 1996. These farms were divided into three groups each year based on the profit index.

There were 138 farms that were either in the high third or low third profit index category for at least five of the six years. In general, farms would either move from the high third to the middle third or the middle third to the low third profit index group. However, some farms did move from the high third to the low third or vice-versa. This finding is consistent with other studies. The movement of farms can be attributed to many factors including weather, changes in the operation or what has been termed "random life events."

The 138 farms formed the population base for the telephone interview survey. There were 73 usable surveys obtained from the phone survey and these farms provided the data used in this study. The distribution of the 73 farms is shown in Table 1.

Table 1. Final Study Sample

Small farms (sales $<\$ 250,000)$

Low Profit

25

Large farms (sales $>\$ 250,000)$ 6
High Profit Total 28

14
20

\section{Comparison of Successful and Unsuccessful Small Farms}

It is important to remember in the following discussions that the farms in the Iowa Farm Business Association are representative of conventional Iowa farms. This means we will not be looking at what is possible for a small farm if they adjust enterprise mix or make other adjustments to accommodate their size. Rather, this is a discussion comparing and contrasting current, conventional Iowa farms.

Remember, too, that this section compares the successful and unsuccessful based on the profit index. The profit index eliminates the size bias and allows for comparison based on how efficiently the farm uses its available resources.

There are several general areas where small successful farms differ from small unsuccessful farms. Some of these factors are not controllable, while others could be controlled. Other variations may simply reflect a difference in attitude or point in life.

In the following discussion, small farms are those with sales of less than $\$ 250,000$ and successful ones are defined as those that were in the top one-third of the profit index grouping at least five of the six years from 1991 to 1996.

The comparison revealed there are economies of size among the small farms. 
The successful farms had statistically significant higher sales and acreage ${ }^{2}$. The successful farms averaged 704 acres while the unsuccessful ones averaged 416 acres. The successful farms averaged $\$ 180,334$ in sales compared to $\$ 109,901$ for the unsuccessful farms. Comparisons based on the median sales reveal an even greater discrepancy. The median sales were $\$ 188,131$ versus $\$ 91,342$ for the successful and unsuccessful farms, respectively.

Several of the significantly different characteristics between the groups of farmers were interrelated. The successful farmers were younger (46 versus 61) and better educated (61 percent had at least some college versus 32 percent) than their counterparts. Conversely, the unsuccessful farms had significantly more years farming experience (38 versus 22).

There was no significant difference in the percent of farmers who listed farming as their principal occupation nor in the percent who reported working off the farm. However, the successful small farms worked significantly fewer weeks off the farm than their unsuccessful counterparts (18 weeks versus 40). As a consequence the unsuccessful small farms reported significantly higher off-farm income, $\$ 18,597$ versus $\$ 7,035$.

A significantly higher proportion of the successful farmers reported working on other farms (43 versus 8 percent).

The successful small farms rented a significantly higher portion of the land they farmed (83 versus 53 percent).

The value of the machinery and equipment and the total machinery expenses were almost identical for the two groups. Given the unequal number of acres and sales, the successful small farms were more efficient in their use of machinery and equipment. On a per acre basis, machinery investment, machinery expenses and depreciation were all significantly lower for the successful farms ( $\$ 112$ versus $\$ 202, \$ 23.73$ versus $\$ 43.23$, and \$16.71 versus \$26.31, respectively).

The small successful farms also were significantly more efficient in their production. Average corn yields were 136 versus 127 bushels per acre and average soybean yields were 48.1 versus 42.5 . The successful and unsuccessful farms were dispersed similarly throughout Iowa so location (at least at the county level) would not account for the yield differences.

The farmers also were compared based on several managerial characteristics. The successful farmers spent significantly more time on marketing than their counterparts $(3.5$ hours per week versus 2.3). In addition, the successful small farms relied more heavily on technology, reporting significantly higher use of the computer. There was no significant difference between the sources of information used except that the successful farmers relied more heavily on market services while the unsuccessful farmers reported a greater reliance on neighbors as a source of information.

\footnotetext{
${ }^{2}$ Throughout this paper, statistically significant difference refers to differences at the 5 percent level.
} 
The farmers were asked to rank the importance of a series of objectives for their farms. For the successful small farms, the top five objectives were being viewed as a good neighbor, spending time with their families, a place to raise a family, making money, and being my own boss. This was the order in which they listed the objectives but there was no significant difference among these objectives.

The unsuccessful small farms ranked their objectives in this order: being viewed as a good neighbor, being my own boss, making money, working outside and working with nature. For the unsuccessful farms, the first three objectives were not significantly different but the top three were reported significantly more often than the last two.

The farmers also were asked to rank the importance of several activities or occurrences in the success of their farms. For the high-profit small farms, the first three activities listed (timing, hard work and attention to detail) were not significantly different in terms of importance. The next two activities cited were accurate information about the farming operation and careful consideration of the available options. For the low-profit small farms, accurate information about the farm and hard work were the first two activities. They were significantly different from the next two, which were timing and attention to details. Finally, the low-profit farms listed government policies as their fifth most important reason for success.

It is interesting to note that the majority of the farmers, 82 percent of the highprofit and 76 percent of the low-profit farms, said that they would still choose farming as a career if they had to make the choice again.

The comparison of the successful and unsuccessful small farms revealed some significant differences. Some of the differences suggest potential areas of improvement where the unsuccessful farms could increase their profitability. However, it is our opinion that most of the differences can be traced to the age differences between the two groups.

The successful farms made better use of the resources that they controlled. They also appeared to make greater use of rented rather than owned resources. The overall level of efficiency (higher yields, and lower costs) is greater for the successful farms;.

The age difference and the farm family life cycle explain many of the differences found. Younger farmers are more likely to rent land because their financial status limits land ownership. On the other hand, older farmers are likely to view land ownership as a source of retirement income and financial security for later years.

Younger farmers are more likely to be innovators and adopt new technologies. Their higher education and youth probably affects both their efficiency and their managerial skills.

It is more likely that the families of the older farmers are grown. This could be one reason why the family-oriented objectives are not cited as often among the less successful farmers. 
Small farms can be successful and they can compete. To be successful, however, they must do at least two things. They must use their resources as efficiently as possible and have a mix of owned and rented resources reflective of their financial position. Small farms also must find their niche. They cannot be successful if they simply try to act as a scaled-down version of their larger counterparts. To be successful, the farmer has to know the resources and have goals consistent with those resources.

\section{Profitability and Perceived Success}

Financial success is only one measure of success, albeit the most frequently used measure. FBA farmers in the telephone survey were asked to rate the success of their farm in achieving their objectives. Their perceptions were recorded on a scale from 1 to 7.

In this section, we compare the perception of the farmers with our success ranking based on the profit index. For this analysis, we will use all the observations, including both large and small farms. In this case the number of observations was 72 .

Table 2 shows the majority of the farmers that rate their farm as successful or somewhat successful in achieving their goals. None of the respondents chose 1 , the least successful, whereas 11 chose 7 , the highest success rating.

Table 2: Distribution of Farms by Profit Index and Perception of Success

\begin{tabular}{cccccc}
$\begin{array}{c}\text { Perceived Success } \\
\text { Index }\end{array}$ & $\begin{array}{c}\text { Large, High } \\
\text { Profit Index }\end{array}$ & $\begin{array}{c}\text { Large, Low } \\
\text { Profit Index }\end{array}$ & $\begin{array}{c}\text { Small, High } \\
\text { Profit Index }\end{array}$ & $\begin{array}{c}\text { Small, Low } \\
\text { Profit Index }\end{array}$ & Total \\
1 & 0 & 0 & 0 & 0 & 0 \\
2 & 0 & 1 & 0 & 1 & 2 \\
3 & 0 & 0 & 0 & 2 & 2 \\
4 & 2 & 0 & 2 & 5 & 9 \\
5 & 2 & 2 & 10 & 9 & 24 \\
6 & 7 & 3 & 12 & 3 & 25 \\
7 & 3 & 0 & 4 & 4 & 11 \\
TOTAL & 14 & 6 & 28 & 24 & 72 \\
\hline
\end{tabular}


It is interesting to note the difference in profit category and perception of success. For the large high profit successful farms, 71 percent felt they were successful while only 57 percent of the small high profit farms rated their success as either a 6 or 7 . On the other hand, 29 percent of the small, low-profit farms felt they were successful. Half of the large, low- profit farms rated themselves as successful, although none of them chose the highest success rating.

The farmers who rated themselves as successful (rating 6 or 7) were compared to the other farmers. In this case there was no significant difference in age or education but the successful farms were significantly larger in both acres (768 versus 467) and average sales ( $\$ 247,720$ versus $\$ 177,327)$. Other size measures such as total assets, gross profits, and net farm income were significantly larger for the successful farms. The average management return was positive for both groups but the $\$ 19,520$ management return for the successful group was significantly higher than the $\$ 819$ for the unsuccessful farms.

Further comparisons were made between the groups with differences in the profit category and the perception of success. There are two ways to compare the different groups. First, we examined the differences between those who said they were successful but had a low profit index. Next, we compared those with a high profit index but who had rated themselves as unsuccessful.

There were 31 farms in the low-profit category, 6 were large farms and 25 were small farms. Of these 31 farms, almost a third (10) rated themselves as successful. There was very little difference in the average age or education between these two groups of farmers.

Those who felt they were successful farmed a significantly higher number of acres even though the average sales were not significantly different between the two groups. The average management return was negative for both groups, but those who ranked themselves as successful actually had a significantly lower average management return $(-\$ 30,920$ versus $-\$ 22,470)$.

This result seems counter-intuitive at first, but those who rated themselves as successful had significantly higher asset values and depreciation. This higher depreciation is what led to the lower management return. It appears that the not-soprofitable farmers who view themselves as successful derive some personal satisfaction or reward from asset ownership even though this does not translate into financial success.

There were 42 farms in the high-profit index category. Of these farms, 62 percent rated themselves as successful. The analysis of the high-profit farms that did or did not perceive themselves as successful revealed very little in terms of significant differences. The successful ones were slightly younger and better educated. They also had larger amounts of acreage and sales but, again, these differences were not significant.

This shows that some farmers view themselves successful even if they are not in the high-profit category or are not operating large farms. This results of this study are consistent with several other studies that have looked at the objectives of farms and farm 
families (Gasson et al., 1988; Gasson and Errington, 1993). It is important to note that the differences among competing objectives are observed in both large and small farms.

\section{Conclusions}

There are significant differences between financially successful and less successful small farms. Some of the differences are in areas where changes can be made while others are not.

Successful small farms used the resources available to them more efficiently than the unsuccessful farms. They also relied on a different mix of owned and rented resources. The successful farms use more rented resources, both land and machinery.

We found that economies of size do exist within small farms. Many of the farms simply do not have the volume of sales to justify the level of expenses incurred. The unsuccessful farms have considerably higher investment per acre and per dollar of sales.

The successful small farmers are younger and better educated. This combination affects many of the attributes where we found significant differences between the successful and less successful small farms. The successful farmers make more use of technology and have better managerial skills than their unsuccessful counterparts.

The age differences also affect the objectives for the farm. The successful small farmers listed family objectives more frequently than the unsuccessful ones, but this difference could simply be due to the fact that the unsuccessful farmers' families are already grown.

Nearly half, 43 percent, of the successful small farmers only perceive themselves as somewhat successful. This may be due to the desire that they have to expand their businesses and earn more income. It also points out that in the future these farms may desire choose to become large farms. Conversely, almost a third, 29 percent, of the nonsuccessful farmers perceive themselves as successful. This indicates that making money is not their primary objective.

Profit maximization is certainly a goal for many farms. However, profit is only one of many goals for the farm family. Many farmers who are classified as financially successful do not perceive themselves as successful and there are farmers who are not financially successful but still perceive themselves as successful.

When examining these different categories of farms. we found that there was little significant difference between them. The main difference was that the less financially successful farms that still perceived themselves as successful were larger than their counterparts. This would seem to indicate that the prestige factor of land ownership is important in determining individual perception of success.

Small farms can compete. They must be efficient and they must use the proper mix of owned and rented resources. They also must compete based on their unique 
attributes. A successful small farm is not simply a scaled-down version of a large farm. The successful small farm takes advantage of its strengths relative to the competition.

When we ask the question, "Can small farms compete?" it is important to remember why we are asking the question and how we measure success. Many small farms are not making the most money but they perceive themselves as successful and, if given the choice again, they would still choose to be farmers. There are more important things than money.

Small farms are important to the United States for more than purposes of nostalgia. Small farms comprise a majority of all farms and they control the majority of owned farmland. Because of this small farms are very important in natural resource and environmental policy (Newton and Hoppe, 2001). The small farms can play a key role in environmental protection or in mitigation of negative effects of farming activities on the environment.

Over the past year we have seen that centralization has its advantages, but it also has its costs. We must ask ourselves: Do we want our food production controlled by only a few? If not, then we must strive to do everything possible to protect all farms, including small farms. 


\section{References}

Fox G., Bergen P. A and Dickson E., 1993: Why are Some Farms More Successful than Others? A review in Hallam A. (ed) Size, Structure, and the Changing Face of American Agriculture. Westview Press, Inc. USA. pp 232-250.

Garcia, P., S. T. Sonka and S. Yoo, 1982: Farm Size, Tenure and Economic Efficiency in a Sample of Illinois Grain Farms in American Journal of Agricultural Economics, Vol.64 No.1, pp.119-123.

Gasson, R. and Errington A., 1993: The Farm Family Business, CAB International, Wallingford, Oxon OX10 8 DE, UK. 290 pages.

Gasson, R., Errington A., Hutson J., Marsden T. and Winter M., 1988: The Farm as a Family Business: A Review, in Journal of Agricultural Economics, Vol.39, No1.pp1-41. .

Hallam, A., 1993: The Importance of Size and Structure in U.S. Agriculture in Hallam A. (ed) Size, Structure, and the Changing Face of American Agriculture. Westview Press, USA pp 1-13.

Hoffman, R., 1996: Size and profitability, in Farm Journal, 120, pp.2-3.

Mishra, A. K., El-Osta H. S. and Steele C. J., 1999: Factors Affecting the Profitability of Limited-Resource and Other Small Farms in Agricultural Finance Review, vol. 59. pp 77-91.

Mosher, M.L and West V.I., 1952: Why Some Farms Earn so Much More than Others. Bulletin No. 558. University of Illinois, Agricultural Experiment Station, Urbana. 40 pages.

Newton D. J. and R. A. Hoppe, 2001: Financial Well-Being of Small Farm Households Depends on the Health of Rural Economies in Rural America, Vol.16, Issue 1, pp.2-11.

Perry, J. and J. Johnson, 1999: What makes a small farm successful? In Agricultural outlook, Nov.1999, ERS/USDA, pp.7-10. 
